\title{
تأثير برنامج تمرينات تأهيلية على انحراف تحدب الظهر لاى تلاميذ المرحلة الإعدادية بمحافظة أسوان
}

*أحمد عبد السلام عطيتو أنوان

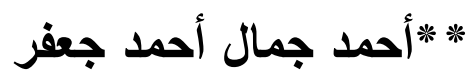

\section{مقدمة ومشكلة البحث}

التربية الرياضية هي جزء من التربية العامة وهي ميدان تجريبي هدفه تكوين

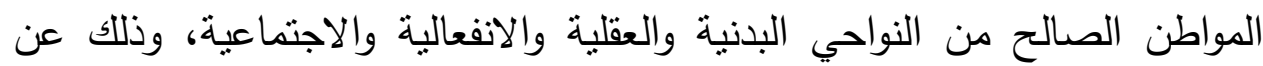
طريق تكوين ألوان من النشاط البدني اختيرت لتحقيق هذه الأغراض ونتيجة لزيادة الاهتمام بالتربية والرياضة في البلاد المتقدمة تحت عناصر عملية ظهرت فاعليتها

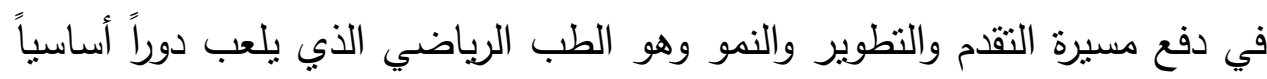

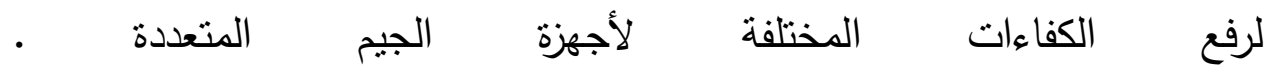
(1):0)

فالقوام السليم أصبح مطلباً ضرورياً في ظل الحياة اليومية التي يعيشها إنسان القرن الواحد والعشرين ، ولقد أسرف الإنسان في استخدام الوسائل التقنية الحديثة

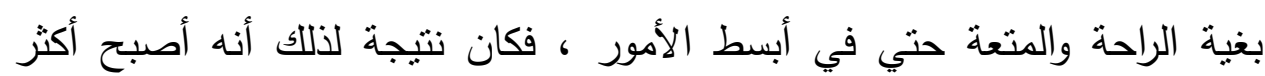

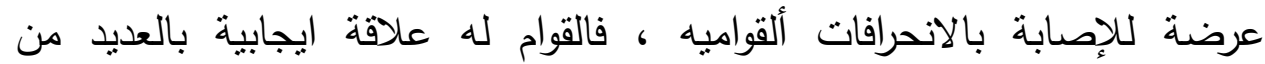
المجالات الحيوية للإنسان ، منها : الصحة ، والثخصية السوية ، والنواحي النفسية

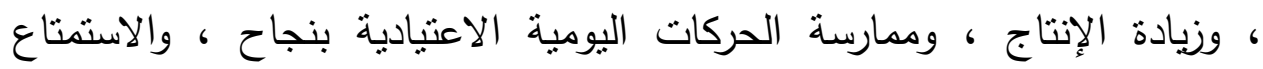

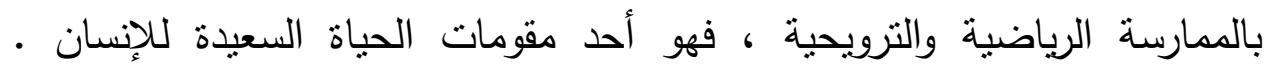
$(19: r)$

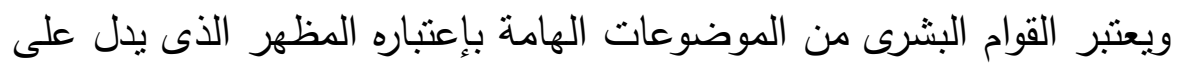

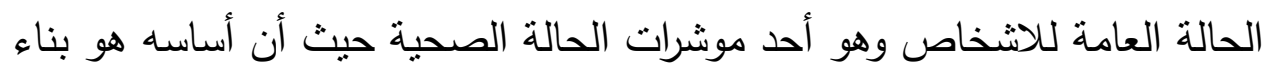


الجسم والتركيب البدنى والتتاسق بين أجزاء الجسم المختلفة ومن خلال القوام يمكن

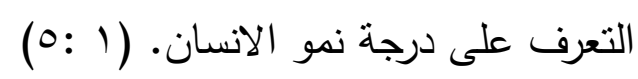
ويتفق كل من محمد صبحى حسانين ومحمد عبدالسلام راغب (r...r.

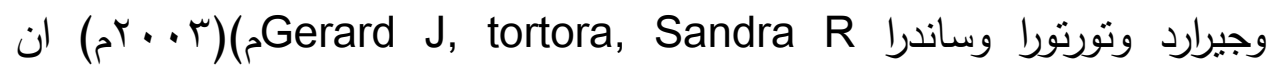
الانحراف القوامى هو تغيرعلاقة عضو من اعضاء الجسم بسائر الاعضاء الاخرى وان القوام المنحرف يكون تغيرا فى شكل عضو من اعضاء الجسم او جزء منه وانحرافه عن المعدل الطبيعى المسلم به تشريحيا مما ينتج عنه تغير فى علاقة هذا

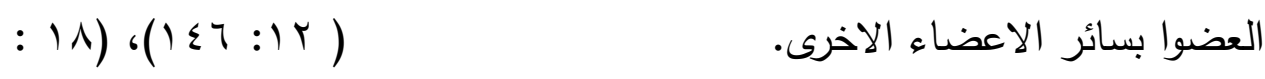

* أستاذ الإصابات الرياضية والتأهيل البذني، رئيس قسم علوم الصحة الرياضية، كلية التربية الرياضية بقنا، جامعة جنوب الوادي. * * باحث بقسم علوم الصحة الرياضية، كلية التربية الرياضية بقنا، جامعة جنوب الوادي.

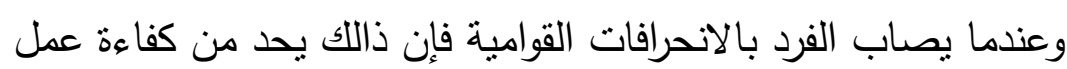
المفاصل والعضلات العاملة في منطقة الانحراف سواء أكان ذلك من الناحية

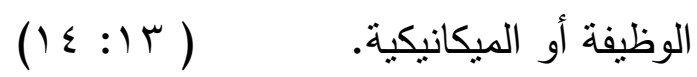


كما نالت مشكلات الإنحرافات القوامية بوجه عام وانحرافات العمود الفقري بوجه خاص قسطا من اهتمام الباحثين بالنسبة للأسوياء في مراحل العمر المختلفة ، علما بأن القوام الجيد من أهم مظاهر حضارة وتقدم الأمم، وقد وضعت الدولة المتقدمة

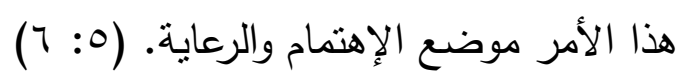

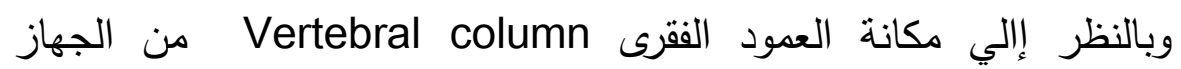
الحركى في جسم الانسان فنجد إنه المحور الأساسى الذى تدور حوله حركة الجسم

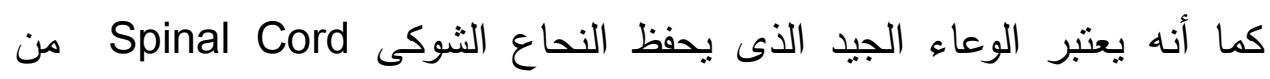
الصدمات الخارجية التى قد يتعرض لها الانسان عند ممارسة الأعمال اليومية، ويتوقف أعتدال القامه وتتاسق جميع أجزاء الجسم على صحة وسلامة وتوازن العمود الفقرى وصحة وإتزان العضلات المتصله به إذ أن أى خلل أو إنحراف بهذه العضلات يخل بالتوازن وبالتالى يؤثر على الأنحناءات الطبيعية للعمود الفقرى مما ينتج عنه ظهور بعض الانحرافات القوامية.

$(179: 1)$

ومن خلال عمل الباحث كمعلم تربية رياضية بإدارة دراو التعليمية بمحافظة

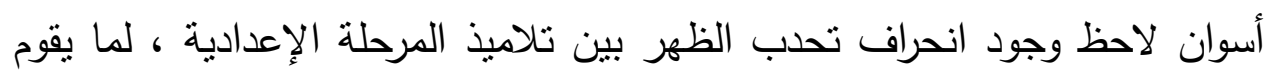

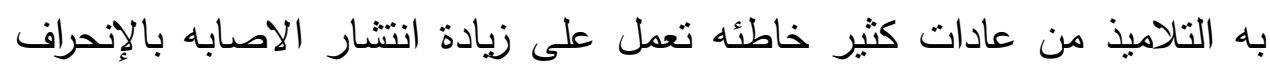
ومن اهم هذه العادات حمل الحقيبة المدرسية التقيله بطريقة خاطئه و عدم تتاسب بله المقاعد الدراسيه لمعظم التلاميذ لان تصميمها لم يراعى الفروق الفرديه بين التلاميذ من حيث الطول والوزن والاصابة ببعض الامراض الخلقيه كضعف النظر وبعض لهض الأمراض النفسية وغيرها وعمل فئه كبيره من التاميذ ببعض الحرف والعض والعادات الخاطئة فى المشي والجرى فكل هذا يؤثز بشكل كبير على اصابة التلاميذ بالإنحراف ، حيث أن هذة المرحلة تتميز بسرعة النمو وحدوث طفرة فى النمو

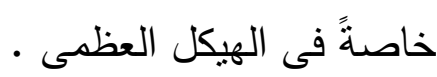


لذا إتجه فكر الباحث إلى تصميم برنامج تمرينات تأهيلية لتحدب الظهر لدى

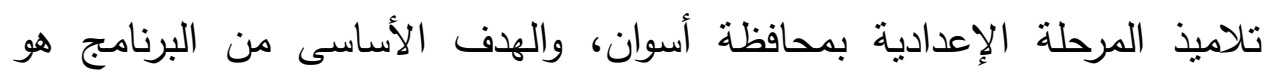
تحسين القوة العضلية لعضلات الظهر والمدى الحركى للعمود الفقرى للتلاميذ.

\section{أهمية البحث : n}

يعد هذا البحث أحد المحاولات العمية التي تخدم المجال الرياضي وانحراف تحدب الظهر ، وتساعد في بناء برامج تمرينات تأهيلية قد يؤدي إلي :

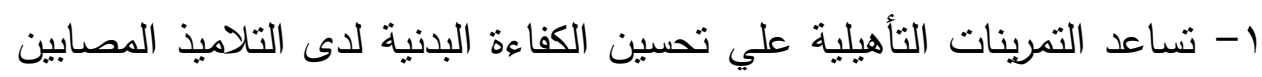

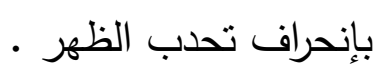

ץ- قد تساعد نتائج الدراسة الحالية القائمين في هذا المجال علي كيفية تخطيط

$$
\text { وتتفيذ مراحل برنامج التمرينات التأهيلية. }
$$

r- قد تحد من خطورة انتشار هذه الظاهرة بين تلاميذ المرحلة الإعدادية بمحافظة

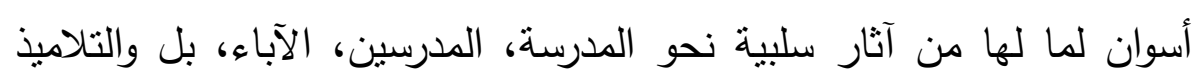

$$
\text { • أنفسهمخ }
$$

ع - قد تكون الدراسة الحالية على حد علم الباحث من الدراسات الأوائل التي تتتاول وضع برنامج تمرينات تأهيلية ومعرفة تأثيرها على بعض المتغيرات البدنية والفسيولوجية لدى تلاميذ المرحلة الإعدادية بمحافظة أسوان.

$$
\text { أهداف البحث : (1) }
$$

يهدف البحث الحالي إلي تصميم برنامج تمرينات تأهيلية على انحراف تحدب الظهر لدى تلاميذالمرحلة الإعدادية بمحافظة أسوان ومعرفة أثزه على:

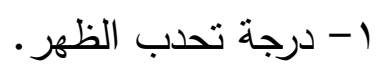

r - بعض المتغيرات الفسيولوجية(السعة الحيوية، النبض).

$$
\text { فروض البحث : بعض }
$$

1- توجد فروق داله احصائياً بين القياس القبلي والقياس البعدي في درجة زيادة تحدب الظهر لصالح القياس البعدي. 


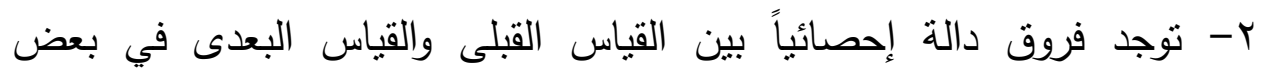

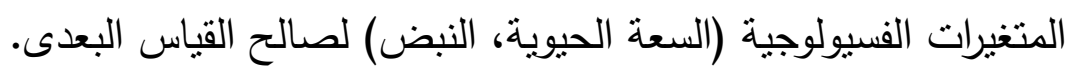

المصطلحات المستخدمة في البحث :

1-تحدب الظهر Kyphosis

هو زيادة غير عادية فى تقوس المنطقة الظهرية من العمود الفقرى للخلف

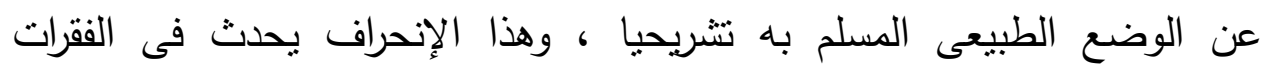
$(r \wedge: r)$

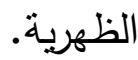

\section{Rehapilitation Exersise :}

هي أحد الوسائل الطبيعية الهامـة في مجال العلاج المتكامل للإصـابات

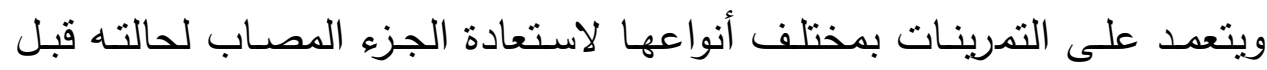

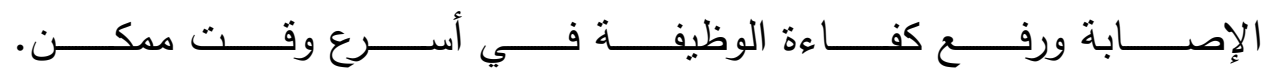
$(\varepsilon \cdot:)$

الانحراف القوامي posture Deformity:

هوالتغير فى شكل عضو من أعضاء الجسم كله أو جزء منة وانحرافه عن الطن

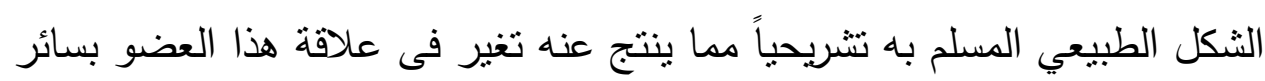

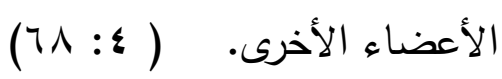

خطة وإجراءات البحث أولاً: منهج البحث واجثرات

تحقيقاً لهدف البحث وفروضه إستخدم الباحث المنهج التجريبى باستخدام

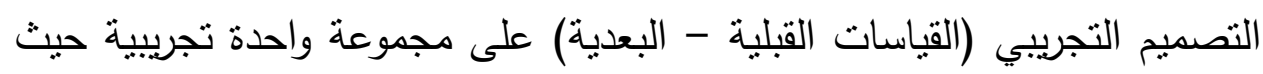
إنه المنهج الملائم لطبيعة البحث. ثانياً: مجتمع البحث 
يمتل مجتمع البحث تلاميذ المرحلة الإعدادية (بنين) في المرحلة العمرية من سن (rا-ـ؛ () سنه والهصابين بانحرافات العمود الفقري(زيادة تحدب الظهر)

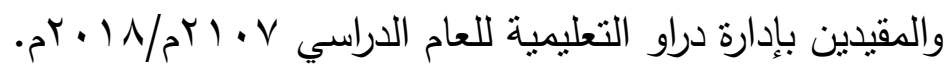
ثالثاً: عينة البحث بائ تم اختيار عينة البحث بالطريقة (العدية) من بين تلاميذ المرحلة الإعدادية

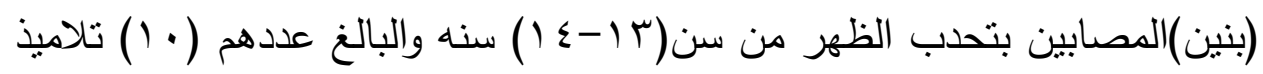
بإدارة دراو التعليمية بمحافظة اسوان.

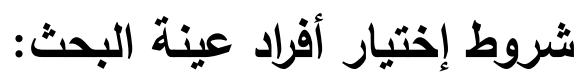

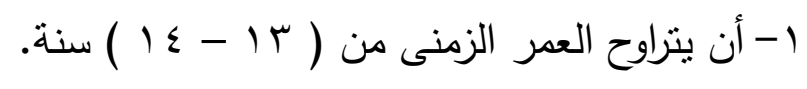

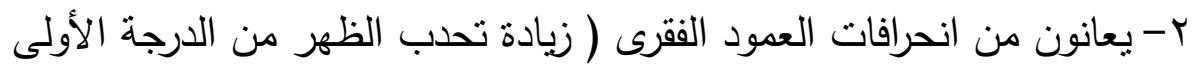

والثانية ).

r- إجتياز الفحص الطبى بواسطة طبيب الددرسة .

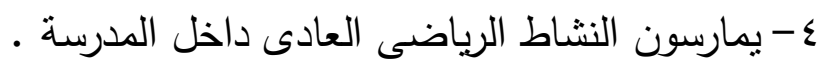

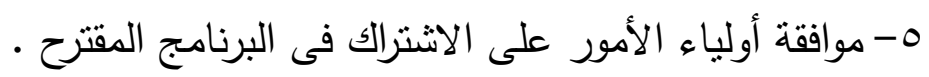

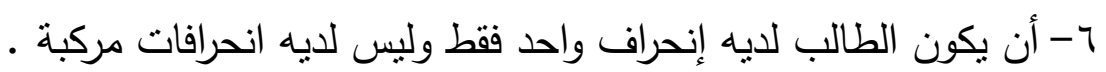

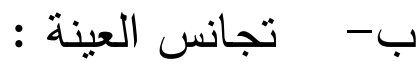




\section{جدول (1) \\ توصيف عينة البحث}

$1 \cdot=\dot{0}$

\begin{tabular}{|c|c|c|c|c|c|c|c|}
\hline $\begin{array}{c}\text { معاملات } \\
\text { الأواء }\end{array}$ & الوسيط & قيمة & قيمة & الانمريارية افات & المسابية & والقياس & المتغيرات \\
\hline 0.021 & 13.00 & 14.00 & 13.00 & 0.510 & 13.55 & سنة & Age السن \\
\hline 1.043 & 60.02 & 70.00 & 55.00 & 3.346 & 60.60 & كجم & الوزن Weight \\
\hline 0.452 & 1.52 & 1.67 & 1.57 & 0.026 & 1.613 & 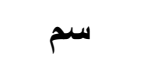 & Height الطول \\
\hline 0.365 & 148.36 & 155.25 & 133 & 3.118 & 149.40 & الارجة & درجة تحدب الظهر \\
\hline 0.157 & 82.57 & 90.05 & 77.05 & 3.654 & 83.10 & نبضة/ق & النبض \\
\hline 1.025 & 996.54 & 1125 & 992.0 & 45.929 & 1077.70 & ملليتر & السعة الحيوية \\
\hline
\end{tabular}

يتضح من نتائج الجدول (1) المتوسطات الحسابية والانحرافات المعيارية لعينة

البحث في المتغيرات المحددة بالجدول ،وقد تراوحت قيم معاملات الالتواء بين

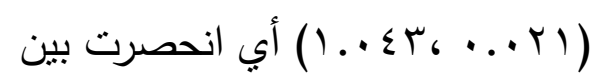

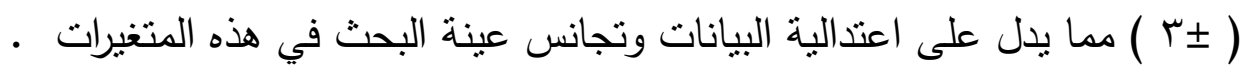

رابعاً: أدوات جمع البيانات

أدوات البحث ووسائل جمع البيانات:

استخدم الباحث لجمع البيانات اللازمة الوسائل المناسبة لطبيعة البحث وهى

كالآتى :

ا - الملاحظات الميدانية Observation

r- المقابلة الثخصية Interview

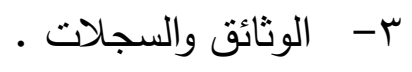

ع - الاختبارات والمقاييس المستخدمة فى البحث .

Observation الملاحظات الميدانية 
من خلال تواجد الباحث ببعض المدارس الاعدادية لاحظ أثثاء ممارستهم

للنشاط الرياضي فى درس التربية الرياضية وفى فترة الراحة التى تعتبر مجالاً

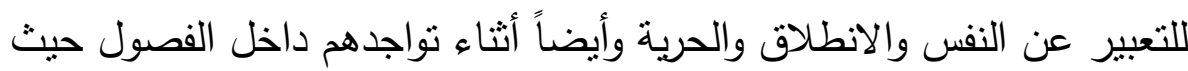
طريقة جلوسهم على المقاعد ، وملاحظة بعض العادات القوامية الخاطئة فى ولى ولى الوقوف والجلوس والمشى .. التى إعتاد عليها هؤلاء الطلاب وبالتالى وجود انحرافات قوامية واضحة و بنسبة ليست بقليلة ، هذه الملاحظات ساعدت الباحث

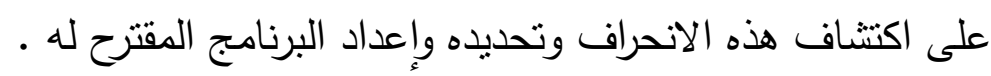

\section{Interview المقابلة الشخصية}

قام الباحث بإجراء بعض المقابلات مع مدرسين ومدرسات تلاميذ المرحلة الاعدادية ومدرسات ومدرسين التربية الرياضية والمسؤلين بإدارة دراو التعليمية التابع

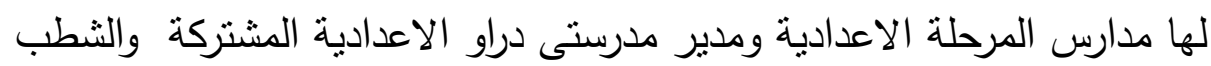

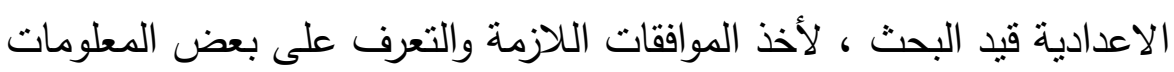

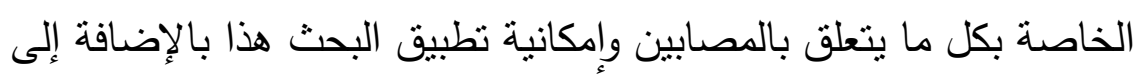

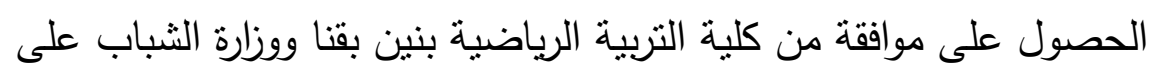

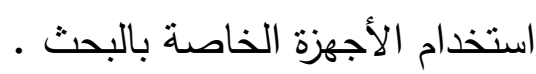

الوثائق والسجلات : الون

إستعان الباحث بالوثائق والسجلات الموجودة بإدارة المدرسة للحصول على

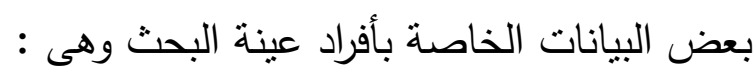

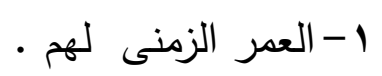

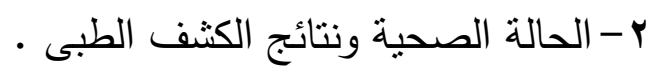

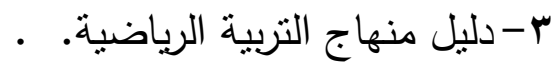

الاختبارات والمقاييس المستخدمة فى البحث :

( ) جهاز الرستاميتر Rastameter لقياس الطوال (سم) والوزن بالكيلو جرام. 
r الميزان الطبى Weight Balance لقياس الوزن (كجم) • ؟) جهاز الأسبيروميتر Sperometer لقياس السعة الحيوية للرئنين (سمץ") ع) إختبار مرونة العمود الفقرى للأمام (سم). 0) جهاز شاثشة القوام لتحديد الانحراف .

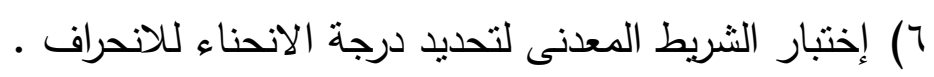

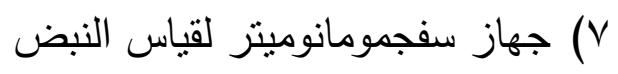

- تم توحيد أدوات القياس المستخدمة فى القياس (القبلى - البعدى ) لجميع

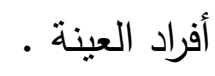

خامساً: خطوات تنفيذ البحث خطوات تنفيذ البحث

بعد تحديد مشكلة البحث وفروضة وعينة البحث ومتغيراته والأدوات المستخدمة فى جمع البيانات ، يتم تتفيذ خطوات البحث طبقاً لما يلى : لإنى التجربة الإستطلاعية

تم إجراء هذه التجربة الاسنطلاعية للتأكد من صحة الإختبارات و الأدوات

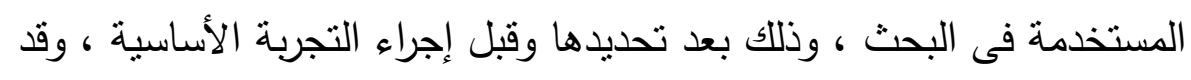

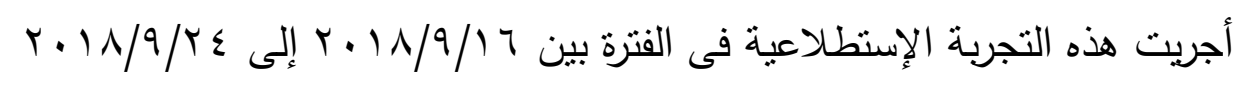

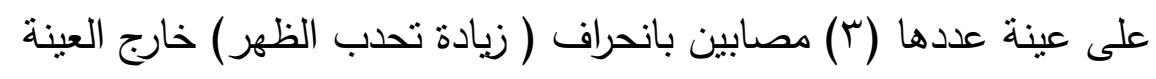
الاساسية بهذف:

1- التأكد من صلاحية الأدوات و الأجهزة لإجراء القياسات . بلات

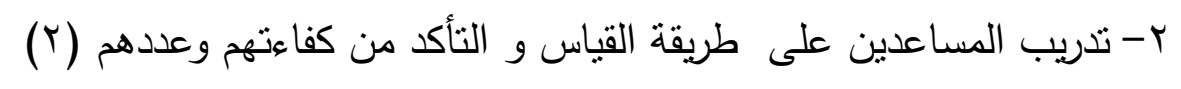

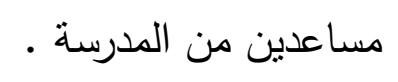

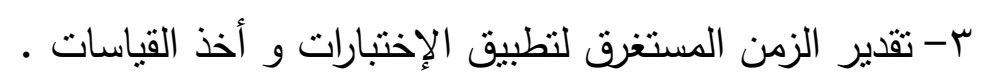

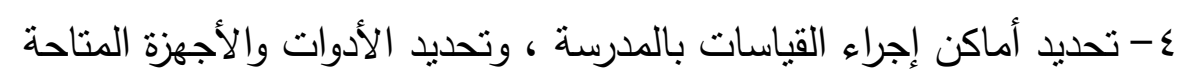

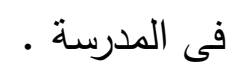


0- تحديد أنسب وقت لتنفيذ القياسات ومعرفة جداول الدراسة والأيام المتاحة -للتطبيق

צ- معرفة الصعوبات التى قد يتعرض لها الباحث عند تتفيذ التجربة الأساسية

والتغلب عليها وقا أسفرت نتيجة هذه التجربة الإستطلاعية على مايلى : 1- تحديد الزمن المستغرق لتطبيق الاختبارات . r- تحديد المساعدين والتأكد من دقة قياسهم . r-تحديد الوقت المناسب لاجراء القاسات مع تجهيز أماكن لإجراء الإختبارات

تصميم و إعداد البرنامج المقترح : تم اعداد وتصميم البرنامج التأهيلى المقترح من خلال الآتى : الاطار المرجعى للبحث

قام الباحث بمسح الإطار المرجعى للبحث من خلال المراجع العلمية العربية والاجنبية الحديثة من أكاديمية البحث العلمى والمركز القومى للبحوث ، وجامعة الإنة

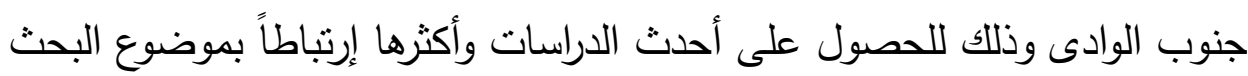

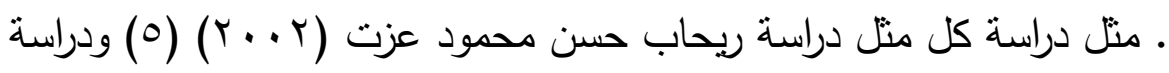

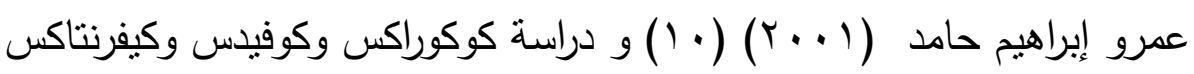

Koukourakis, Giaourakis G., Kouvidis G., وآخرون Kivermitakis Blazos J الإعدادية، لمعرفة أكثر الانحرافات القوامية شيوعا لهذه المرحلة. خطوات تنفيذ البرنامج المقترح (التجرية الأساسية)

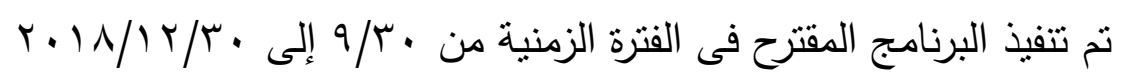
على المجموعه التجريبية ، وتتفيذ درس التربية الرياضية ، وقام الباحث بإجراء القياسات لجميع أفراد عينة البحث وفقاً للإجراءات الآتية: 
أجريت هذه القياسات للمجموعه التجريبية فى جميع متغيرات البحث وذلك

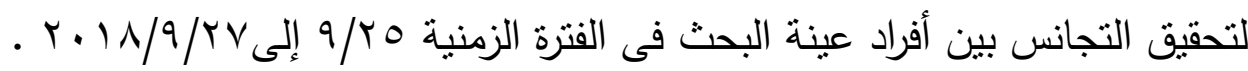
تطبيق البرنامج

تم تطبيق البرنامج المقترح على (• (1) تلاميذ لمجموعة (زيادة تحدب

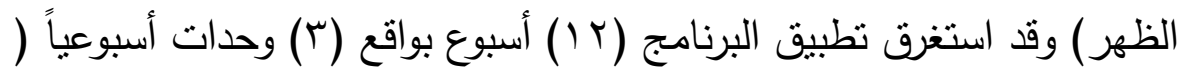
الأحد - الثلاثاء - الخميس) للمجموعة التجريبية الأولى (مجموعة تحدب الظهر) ويبدأ البرنامج بـ (0 اق) ثم يتدرج إلى ( • اق) فى نهاية البرنامج ويصبح محتوى

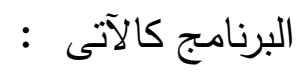

\section{القياسات البعدية}

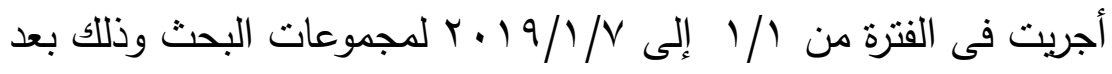

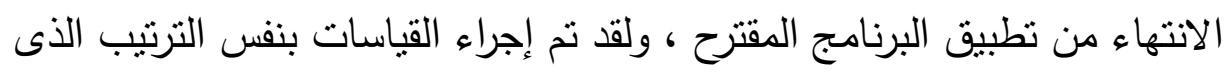
اتبع فى القياس القبلى وذلك لتوحيد ظروف القياس • جمع وتفريغ البيانات

بعد نطبيق القياسات قيد البحث وتسجيل النتائج قام الباحث بتفريغ البيانات ثن وضعها فى صورة جداول يسهل معها المعالجة الاحصائية. المعالجة الاحصائية

$$
\begin{aligned}
& \text { 1- المتوسطات الحسابية } \\
& \text { r- الانحرافات المعيارية } \\
& \text { r- معاملات الالتواء }
\end{aligned}
$$

ع - نسبة التحسن النسبة المئوية لمعرفة مقدار التحسن بين مجموعة البحث فى

$$
\text { متغيرات البحث. }
$$

0- قيمة (ت) لدلالة الفروق. عرض النتائج 
يتتاول هذا الفصل عرضاً للنتائج التى تم التوصل إليها من خلال المعالجات الإحصـائية لبيانـات البحث، ووفقاً للأهداف وفروض البحث يمكن عرض نتائج

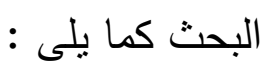

عرض ومناقثـة النتائج الخاصـة بتأثنير البرنـامج التأهيلى لمجموعـة انحراف

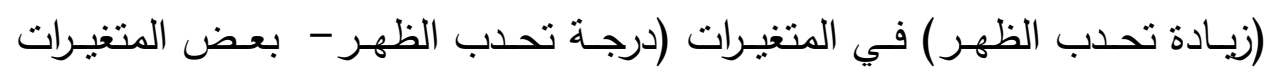
الفسيولوجية (السعة الحيوية، النبض)) لدى تلاميذ المرحلة بمحافظة أسوان.

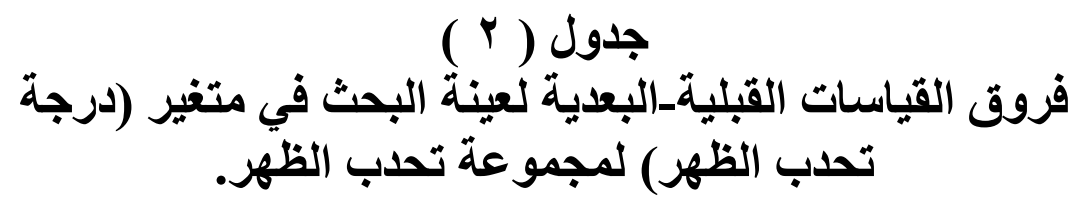

\begin{tabular}{|c|c|c|c|c|c|c|}
\hline \multirow{2}{*}{ قيمة ت } & \multicolumn{2}{|c|}{ القياس البعدي } & \multicolumn{2}{|c|}{ القياس القبلي } & \multirow{2}{*}{ القياس } & \multirow[t]{2}{*}{ لمتغيرات } \\
\hline & $\varepsilon$ & r & $\varepsilon$ & r & & \\
\hline 13.384 & 3.180 & 155.70 & 3.118 & 149.40 & الدرجة & درجة تحدب الظهر \\
\hline
\end{tabular}

* دال احصائياً

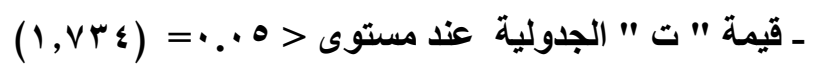

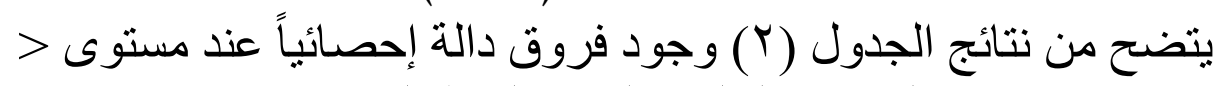

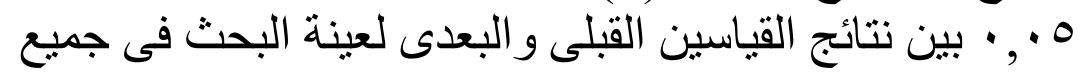

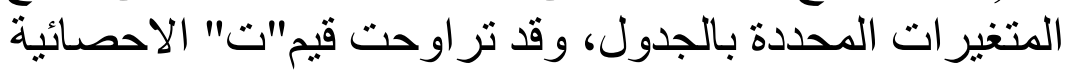
.( (IT.M 


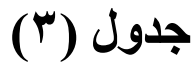

فروق القياسات القبلية_البعدية لعينة البحث في المتغيرات الفسيولوجية لمجموعة تحدب الظهر.

$1 \cdot=$

\begin{tabular}{|c|c|c|c|c|c|c|}
\hline \multirow{2}{*}{ قيمةت ت } & \multicolumn{2}{|c|}{ القياس البعدي } & \multicolumn{2}{|c|}{ القياس القبلي } & \multirow{2}{*}{ القياس } & \multirow[t]{2}{*}{ لمتغيرات } \\
\hline & $\varepsilon$ & م & $\varepsilon$ & م & & \\
\hline 5.536 & 1.732 & 77.50 & 3.654 & 83.10 & نبضة/ق & النبض \\
\hline 19.147 & 67.896 & 1455.40 & 45.929 & 1077.70 & ملليتز & الحيوية \\
\hline
\end{tabular}

$$
\begin{aligned}
& \text { *دال احصائياً }
\end{aligned}
$$

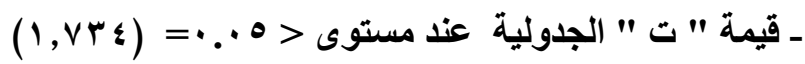

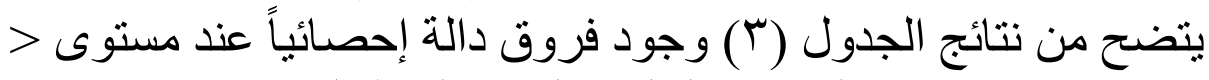

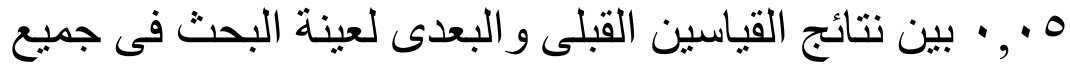

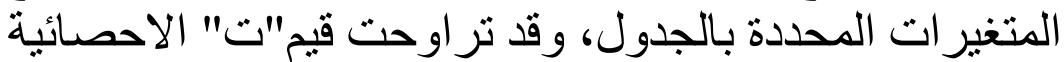

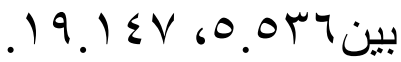

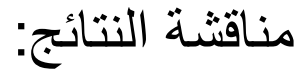

ويرجع الباحث التحسن الذى طرأ على مجموعة (تحدب الظهر )، والفروق

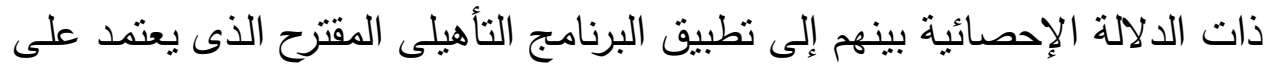

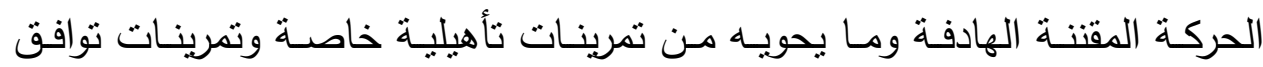
عضلى عصبى وتمرينات بنائية عامة شاملة لتتمية وتطوير بعض عناصر اللياقة

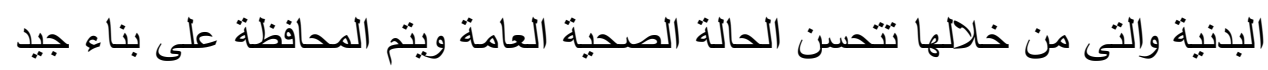
للجسم لاى تلاميذ المرحلة الإعدادية بمحافظة أسوان خاصة خلال فترة النمو.

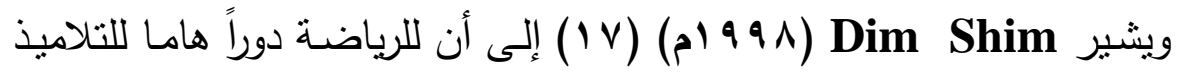

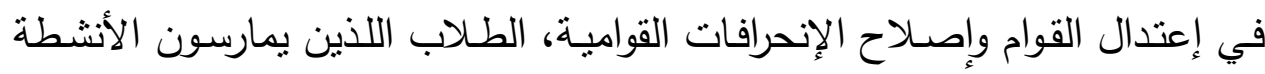
الرياضية المختلفة تتخفض لديهم الإنحرافات القوامية. 


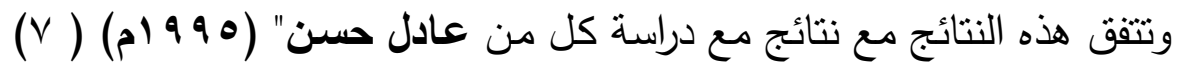

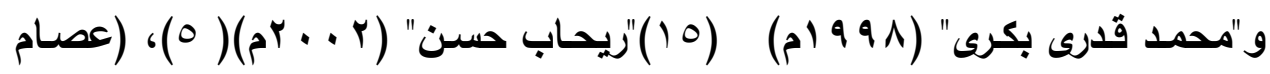

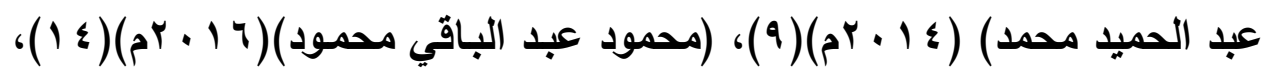

أن برنامج التمرينات التأهيلى المقترح له الأثر الإيجابى فى تحسين الحالة القوامية التهمية

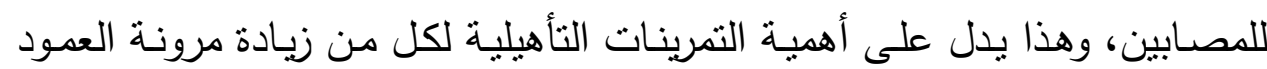

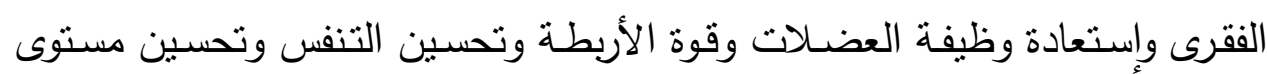

الوظائف الفسيولوجية وتتمية عناصر اللياقة البدنية المختلفة وتأهيل الجهاز الدورى

والعضلى والعصبى وبالتالى تحسين الحالة الصحية العامة.

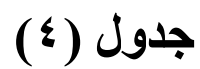

نسب التحسن للقياسات القبلية_البعدية لعينة البحث في متغيرات

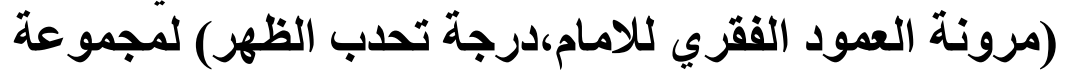

تحدب الظهر.

$1 \cdot=\dot{0}$

\begin{tabular}{|c|c|c|c|c|c|c|}
\hline \multirow{2}{*}{ التحسب } & \multicolumn{2}{|c|}{ القياس البعدي } & \multicolumn{2}{|c|}{ القياس القبلي } & \multirow{2}{*}{ والقياس } & \multirow[t]{2}{*}{ المتغيرات } \\
\hline & $\varepsilon$ & م & $\varepsilon$ & م & & \\
\hline 82.75 & 0.618 & 2.90 & 0.025 & 0.50 & الدرجة & مرونة العمود الفقري للامام \\
\hline 4.21 & 3.180 & 155.70 & 3.118 & 149.40 & الدرجة & لدرجة تحدب الظهر \\
\hline
\end{tabular}

يتضح من نتائج الجدول ( ع ) نر اوحت نسب التحسن بين

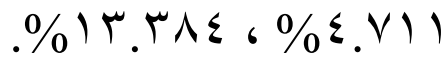




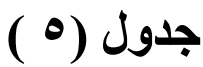

نسب التحسن بين القياسات القبلية_البعدية لعينة البحث في المتغيرات الفسيولوجية لمجموعة تحدب الظهر.

$1 \cdot=\dot{0}$

\begin{tabular}{|c|c|c|c|c|c|c|}
\hline \multirow{2}{*}{ التحسب } & \multicolumn{2}{|c|}{ القياس البعدي } & \multicolumn{2}{|c|}{ القياس القبلي } & \multirow{2}{*}{ والقياس } & \multirow[t]{2}{*}{ المتغيرات } \\
\hline & $\varepsilon$ & م & $\varepsilon$ & م & & \\
\hline 6.73 & 1.732 & 77.50 & 3.654 & 83.10 & ن/ق & النبض \\
\hline 35.04 & 67.896 & 1455.40 & 45.929 & 1077.70 & ملليتز & السعة الحيوية \\
\hline
\end{tabular}

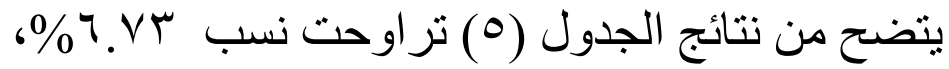

.$\%$ \% . .

\section{الاستنتاجات والتوصيات \\ أولاً: الاستنتاجات التاتهات}

بعد عرض النتائج التي توصل إليها الباحث في ضوء عينة البحث استخلص

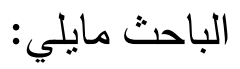

1- وجود فروق دالة إحصـائياً بين متوسطات القياسـات القبليـة والبعديـة فى

تحسن درجة الإنحرافات القوامية (زيادة تحدب الظهر) لدى تلاميذ المرحلة

الإعدادية بمحافظة أسوان لصالح متوسطات القياسات البعدية.

r- وجود فروق دالة إحصـائياً بين متوسطات القياسـات القبلية والبعديـة في

تحسن بعض المتغيرات الفسيولوجية (قيد البحث) لعينـة البحث من تلاميذ

المرحلة الإعدادية بمحافظة أسوان لصالح متوسطات القياسات البعدية.

r- التصرينات التأهيلية الحركية الخاصة داخل البرنامج المقترح لها تأثنير فعال

وإيجـابى فى تأهيـل إنحرافـات (زيـادة تحدب الظهر ) لدى تلاميذ المرحلـة

الإعدادية بمحافظة أسوان لصالح متوسطات القياسات البعدية.. 
ع - التمرينات التأهيلية الحركية الخاصة بالبرنامج يؤديها التلاميذ بكفاءة عالية وحماس وذلك إستتاداً لملاحظة الباحث أثناء البرنامج. ثانياً: التوصـيات

في ضوء هذا البحث وفي حدود القياسات التي تم إجراؤها لعينة البحث وما

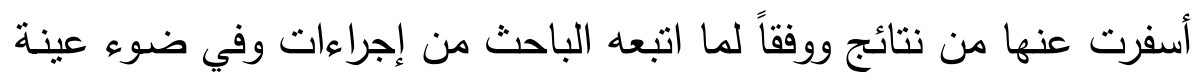
البحث يوصى بما يلي:

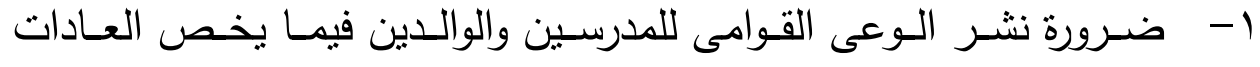

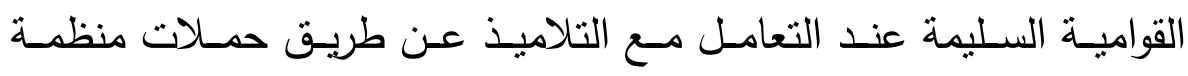

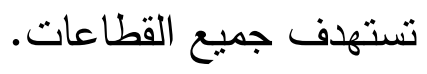
r- تقديم البرنامج التأهيلى للجهات التعليمية (المدارس الاعدادية - الجمعيات

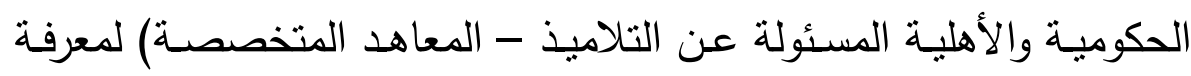

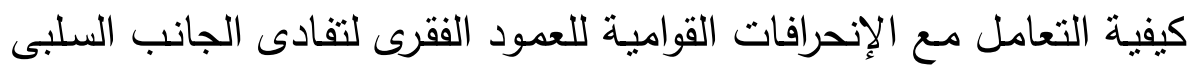
لها. ץ- الإهتمـام بهذه النوعيـة من البـرامج التأهيليـة وإدخـال المدارس الاعداديـة

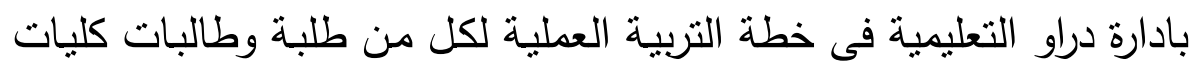
التربية الرياضية. ع- الإهتمام بالكثف القوامى بين التناميذ وفى بداية كل ترم دراسى لإكتثاف الإنحرافات القوامية مبكراً. 0- إجراء دراسات وبحوث تستهدف تحديد الإنحرافات القوامية المنتشـرة بين فئات التلاميذ فى المجتمع مثل (المراحل الابتدائية - المدارس الخاصـة )

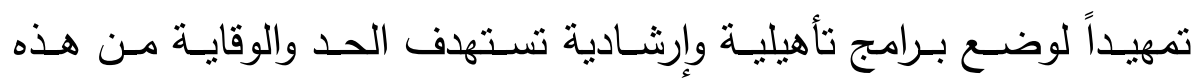

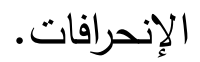
צ- تنفيذ البرنامج التأهيلى لتأهيل إنحراف (زيادة تحدب الظهر). 
الإهتمام بعقد ندوات دورية بشارك فيها المتخصصون فى مجال العلاج البدنى التئي

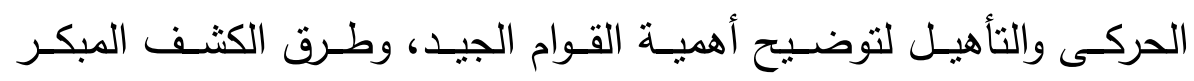

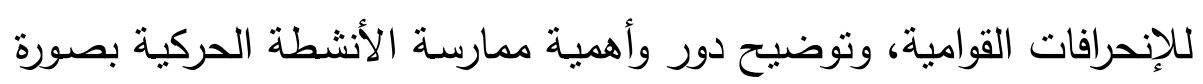

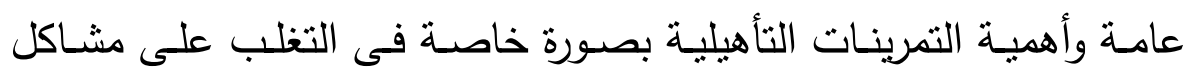

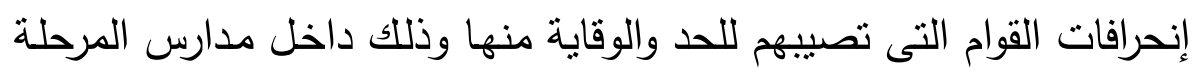

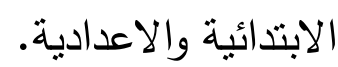
إدخال البرنامج التأهيلى الحركى ضمن أجزاء الدرس اليومى للتربية الرياضية

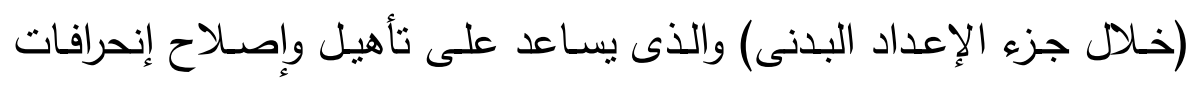

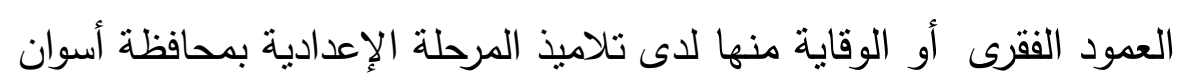




\section{المراجع}

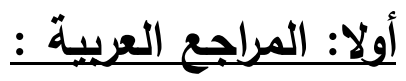

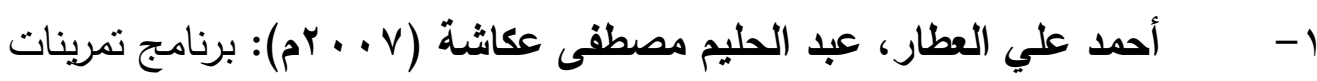
تأهيلية لاستعادة القدرة الوظيفية لمفصل الفخذ بعد جراحة زراعة مفصل صناعي بديل،

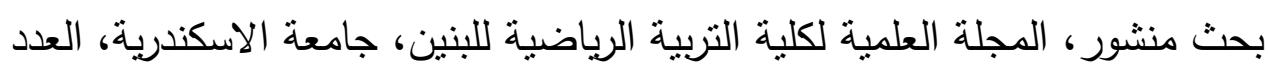

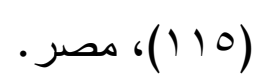

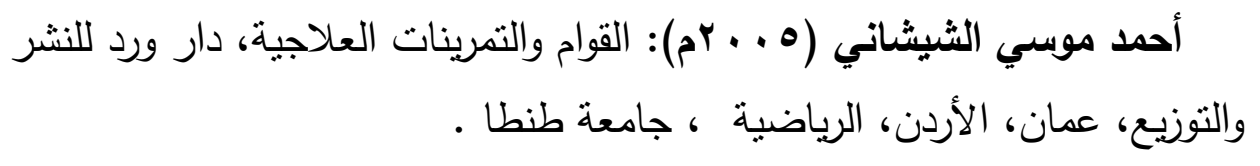

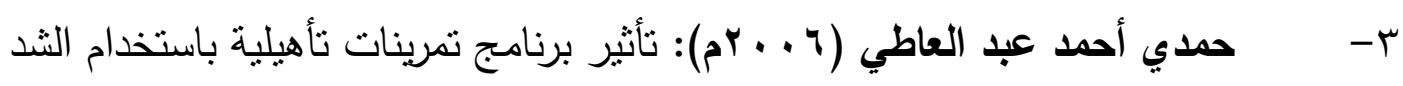
العلاج خشونة الرقبة، رسالة ماجستير ، كلية التربية الرياضية، جامعة طنطا، مصر •

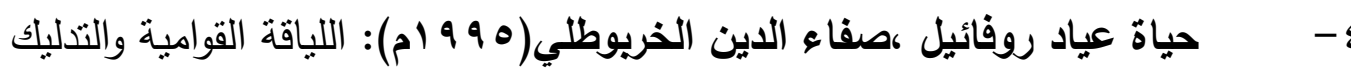

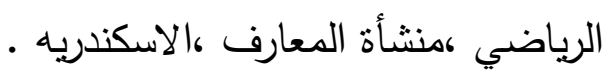

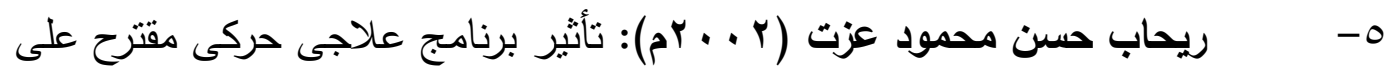
بعض الصفات البدنية وعلاقتها بإنحرافات العمود الفقري للمعاقين ذهنياً ، رسالة دكتوراة

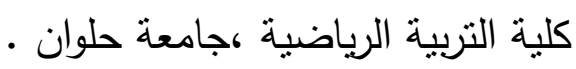

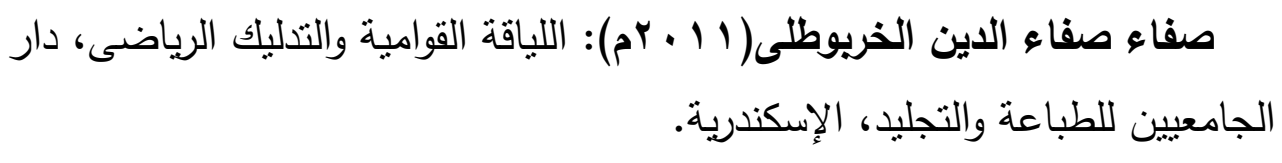

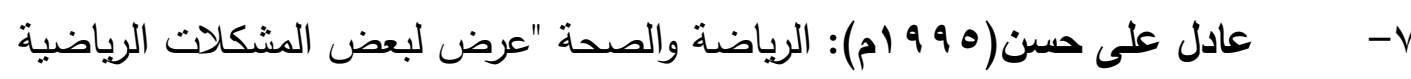

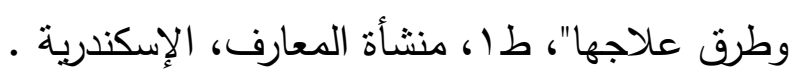

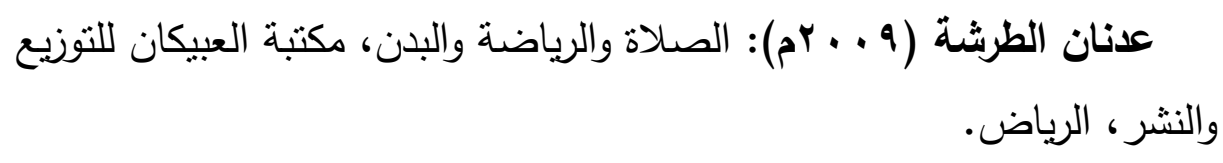
العمود الفقري لديالمرحلة العمرية من ( • ( الحميد محمد : نأثنر التمرينات التأهيلية المائية علي بعض رسالة ماجستير غير منشورة، انحرافات $-9$ 
كلية التربية الرياضية، جامعة جنوب الوادى، ع ( • بر.

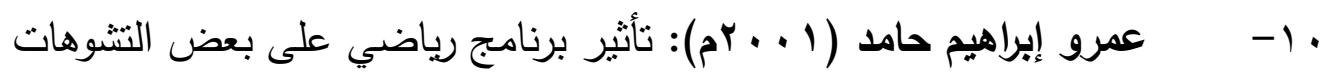

القوامية لدى تلاميذ المرحلة الإعدادية، رسالة ماجستير غير منشورة، كلية التربية

الرياضية للبنات بالقاهرة، جامعة حلوان.

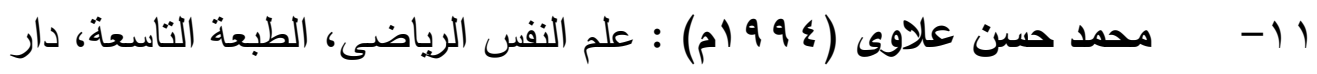

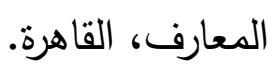

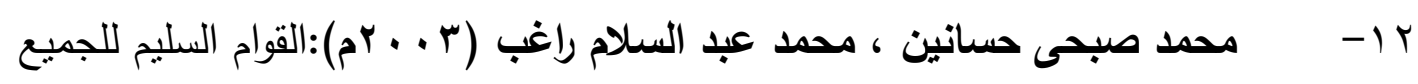

$$
\text { ، الف ار الفكر العربى ، طب، القاهرة. }
$$

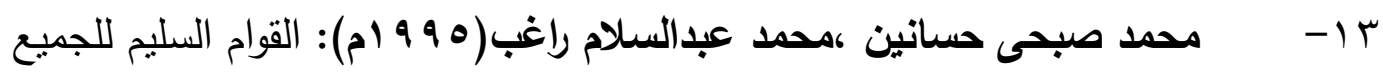
كدار الفكر العربى ،القاهرة.

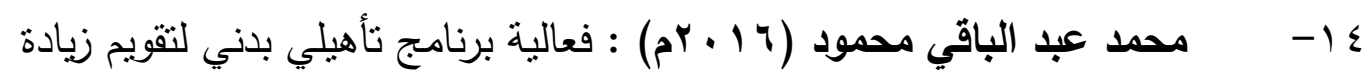

تحدب الظهر لدي أطباء الاسنان ، رسالة ماجستير غير منشورة، كلية التربية

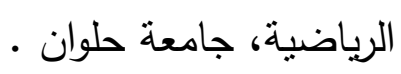

10- محمد قدرى بكرى (99191م): الإصابات الرياضية والتأهيل الحديث، مركز الكتاب

لـنشر

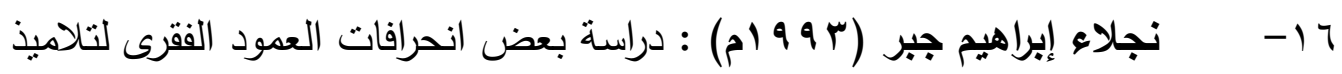

مــن(ج-9) سنوات بمحافظة بورسعيد ، رسالة ماجستير غير منشورة ، كلية التربية

الرياضية ببورسعيد ، جامعة قناة السويس .

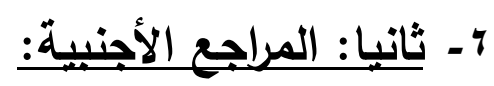

17 Dim shim G.B(1998): "Variations Of Sitting Posture and Physical Activity in Different Types of School" Instital for Anthrpology.

$1 \varepsilon$ Gerard J, tortora, Sandra R(2003):principles of anatomy and hysiology, tenth editior, publisher john wiley \& sons, Inc, USA .

1c Koukourakis I., Giaourakis G., Kouvidis G., Kivernitakis and Blazos J., (1999):Sereening school children for scoliosis on the island of crete, spinal disord . 